Proceedings

\title{
Technoetic Aesthetics of Revelation and Transcendence: The Horse in the Mind
}

\section{Lila Moore}

Zefat Academic College, Jerusalem St 11, Zefat, Israel

lila.mo@zefat.ac.il

Cybernetic Futures Institute, London, UK

info@cyberneticinstitute.com

Presented at Apocalypse in the Art: The Creative Unveiling, CenSAMM Symposia Series 2018, Centre for the Critical Study of Apocalyptic and Millenarian Movements, Panacea Charitable Trust , Bedford, UK, June 28-29 2018

Keywords: technoetic arts, apocalypse, transcendence, SpaceX Starman, Blade Runner, consciousness, Kabbalah.

Abstract: The presentation utilizes the sensibility of technoetic aesthetics in order to demonstrate an interpretive study of imagery issuing from contemporary cultural and technological innovative products and events, such as Blade Runner 2049 and SpaceX Starman, the Tesla Roadster launch. It refers in particular to the theme of horse, horseman, and rider depicted explicitly or implied through aesthetic metaphors. These images seem to conjure current apocalyptic and revelatory meanings as well as amplify a sense of collective longings for transcendence.

\section{Introduction}

In this paper I utilize the sensibility of technoetic aesthetics in order to demonstrate an interpretive study of imagery issuing from contemporary cultural and technological innovative products and events, in particular the film Blade Runner 2049 and SpaceX Starman, the Tesla Roadster launch. I reflect on the theme of horse, horseman, and rider which is depicted explicitly or implied through aesthetic metaphoric imagery and vistas generated by innovative technological artifacts, systems, and their performance. These images seem to conjure current apocalyptic concerns, on one hand, and revelatory meanings with a sense of hope, on the other hand, which, together invoke collective longings for transcendence.

Firstly the term 'technoetic' is explained including its correspondence with the sensibilities of mystical traditions of Kabbalah, e.g., Tikunei haZohar and in particular the ecstatic Kabbalah of Abraham Abulafia. Secondly, on 
this technoetic premise, the analysis unfolds the revelatory function of the horse in the mind of $\mathrm{K}$, the protagonist of the post-apocalyptic film Blade Runner 2049, and its aesthetics of transcendence as a product of mind technology. It is followed by a creative reflection on the broadcast of SpaceX Starman, including observations inspired by graphs produced by the Global Consciousness Project (Moore, 2018a), and the color scheme of the 'transcendent rider' in relation to the colors of the Four Horses of the Apocalypse in a Judeo-Christian context.

\section{Technoetic Context}

To begin with, it is critical to introduce the technoetic context of this presentation. The term 'technoetic' was coined by the British artist and theorist Roy Ascott, and pertains to combinations of tech and nous, that is, technology and mind (Ascott, 2003a:341). Broadly, in Greek philosophy (Menn, 1992) the nous pertains to a deeply intuitive intellectual apprehension of first principles and truths. It is also a theological concept referred to as the active intellect of the gods or the divine. In principle, technoetic aesthetics bypasses the surface image of the world and allows an interpretive creative process that considers the interrelations of technology and mind including their various religious and spiritual contexts.

\subsection{Kabbalistic Context}

Interestingly, the imagery of the horse and the rider evokes the interrelations of mind and technology also in the mystical traditions of the Kabbalah. In Tikunei haZohar, or Rectifications of the Zohar in English, which is a main Kabbalah text first published in 1558 CE, the Hebrew letters, which are perceived as divinely originated, are described as horses leading a chariot. The horse in this framework is depicted as a body of letters and the vowels are the soul that determines the direction, movement and sound quality of the body that steers the chariot (Tikunei haZohar: The Fifth Tikun). In this way, the chariot as an advance mystical technology is driven by a divinely infused horse, which is in itself a body comprised of intellect and soul.

During the thirteenth century, the Spanish-born Abraham Abulafia, the prominent exponent of ecstatic Kabbalah, disseminates his messianic and redemptive teachings mainly in southern Europe. Abulafia's path, according to Moshe Idle (1987) produces a synthesis between Maimonides' aristotelian understanding of prophecy as the result of the transformation of the intellectual influx, the nous from the active intellect into a linguistic message and techniques. Prophetic experiences were induced by means of combinations of letters and their pronunciation, breathing exercises, contemplation of parts of the body, movements of the head and hands, and 
concentration exercises. Some of the elements of those techniques stem from commentaries on Sefer Yezirah of Jewish German Ashkenazi origin, while others reflect influences of Yoga, Sufism, and Hesychasm. Abulafia devises techniques for the attainment of ecstasy and prophecy, which he comprehends as the goal of the mystical path, achieved through revelation and union with the divine.

For example, he develops techniques for the summoning of the mystic's double as manifested in the height of a trance-induced ecstatic state (Idel, 1990). The vision of the double is comprised of an image that reflects the active intellect as it is rendered by the mystic's imagination. Thus, the revealed manifested image is based on an influx of nous from the active intellect of the divine that the double mirrors. To achieve the prophetic mystical experience, Abulafia's techniques involve trembling. He describes the mystic's body as a rider racing a horse joyfully and ecstatically while the horse trembles beneath him. Abulafia writes that the mystic rides his intellect as if it were a horse, hitting it with a whip to ensure that his imagination stands where his intellect wills, a sign of great power and truth (Idel, 1987:70). Hence, the horse represents the nous, the highest degree of active intellect that after much training can manifest the purified, crystal clear and mirrorlike imagination into an external revelatory form. Moreover, Abulafia's prophetic books of revelations include apocalyptic imagery and scenes that are interpreted as pointing to spiritual processes of inner redemption. Overall, I here imply that Abulafia's mystical technique is quintessentially technoetic in principle and aesthetics. Intriguingly, Philip K. Dick, the author of Do Androids Dream of Electric Sheep? (1968) on which Blade Runner is loosely based, confessed that he collaborated with the spirit of Abulafia whilst writing VALIS (Dick, 1993: 225).

\section{Horse and Mind in the Blade Runner Films}

Considering this framework of ideas relating to the horse and rider as aspects of the nous and the active intellect, I next observe the notion of the horse as linked to the mind in the Blade Runner films. In the original film by Ridley Scott from 1982, (the director's cut version) the central protagonist Rick Deckard is a Blade Runner, which is his job title as exterminator of replicants. The replicants are highly advanced bioengineered androids that challenge humans physically, emotionally and intellectually. In a mesmerizing atmospheric scene, Deckard is shown slumping drunkenly over the piano, hitting the piano keys with one finger, then his sleepy eyes suddenly opening. At that point we see the vision that transpires in his mind's eye. Interestingly, it's not an ordinary dream but a mental vision of a magnificent white unicorn running in a forest towards him and the screen, filling it whilst turning his 
head streaming. As the unicorn fills the screen, there is a fusion between the film screen and the screen of Deckard's consciousness. The viewer's consciousness is also immersed in the vision of the unicorn. The image could be seen metaphorically as the manifestation of the active intellect, steering the plot in an enigmatic direction. The vision disappears and Deckard, who looked at the vision perplexed, returns to normal consciousness. Thus, Deckard's vision is not merely a dream but may be deciphered as a noetic reflection in which the active intellect and the imagination produce together a crystal-clear apparition of a unicorn as a prophetic messenger. The unicorn, a symbol of pure love and virginity, is in the film linked to Deckard and Rachel, the replicant he falls in love with.

In light of the plot development in Blade Runner 2049, (2017, directed by Denis Villeneuve) the unicorn can now be interpreted as a coded prediction of a miraculous birth, and the arrival of a brand new species of humanoids, with the first humanoid child born of a female replicant, Dr Ana Stelline, the hidden unlawful child of Deckard and Rachel. Ana lives in an isolation capsule due to genetic illness. She plants her childhood memory of a wooden horse back into the collective consciousness of her race in her professional capacity as the chief designer of replicants' memories. But in the case of the leading protagonist replicant K, also a Blade Runner, to whom the memory of the wooden horse was implanted by Ana, the horse becomes a tangible object. It is no longer only a memory, a dream or vision, but an actual object that exists in both abstract mind and tangible reality. In K's world, only those who are born possess a soul and replicants like him who are manufactured artificially do not. The replicants are psychologically sustained by artificial designer memories, however, K's memory of a horse was implanted via a transgressed act as it is considered taboo to implant an actual human memory into a replicant. This act of transgression has great ramifications.

In the post-apocalyptic world of Blade Runner 2049, humanity is being annihilated in stages, beginning with the collapse of the ecosystems, followed by the breakdown of computerized systems and deletion of all digital data, and most drastically, human consciousness continues to transfigure through complex hybrid android life forms that draw on humanity's philosophical and ethical principles of the good, the true and the beautiful (Metz, 2011).

Indeed, the film ends with the words of Dr Ana Stelline, capturing and sharing K's last lived memories, as he absorbs the beauty of snowflakes that fall softly on earth and on his injured dying body. K, who has found true and good meaning and purpose in his life, dies contemplating beauty, the beauty of snowflakes. Immersed in K's memory through his experience of consciousness, Ana says: 'Beautiful, isn't it?' 


\section{Towards Technoetic Kabbalistic Mystical Aesthetics}

In Blade Runner 2049, the horse becomes a metaphor for the preciousness of conscious life, the invaluable gift of soulful memory that shapes a meaningful existence. Moreover, the horse may be perceived as a transcendent symbol belonging to a new people both with and without a soul in the conventional sense of the term. The soul may take on new meanings. In light of the Kabbalistic motif of the horse as both body and soul as well as the manifestation of the divine intellect, $\mathrm{K}$ as the rider of his horse indeed senses a powerful trembling in his body and emotions, which are associated with the disclosure of his true identity and destiny.

Although $\mathrm{K}$ finds out that he is, after all, a replicant, unborn and soulless, the horse in his mind has functioned as a technoetic devise, a carrier of an ensouled nous and comprehension, and above all granted him the realization, and the lived experience, of a dimension of transcendent aesthetics of the good, the beautiful and the true. What is more, the horse as a prophetic messenger of the divine intellect is also associated with a shared revelation concerning the collective destiny of K's people. The replicants, who claim to excel humanity's exploitation of the mind and schemes of controlled procreation, conspire to set themselves free, and become 'more human than human'.

Although Blade Runner 2049 addresses current concerns regarding the disintegration and transfigurations of our human biological and moral constitutions as a result of advancing technologies, it also proposes a reflection on the potential virtues of an age of singularity (Kurzweil, 2005).

While the film viewers are immersed in K's last experience in consciousness in 3D, one may ponder a future, not that far away, where technology and nous as mind, is utilized in a similar manner to Abulafia's Kabbalistic techniques. In this way, technology and nous could perhaps be harnessed to interweave and explore profoundly mystical aesthetics and revelatory visions.

\subsection{The Tesla Roadster's Starman}

On February 6, 2018 over 2.3 million people came together online to watch SpaceX's Falcon Heavy launch. It was YouTube's second biggest live stream ever involving millions of concurrent views. The performative dimension of the event was promoted with a special trailer (SpaceX, 2018). It was infused deliberately to stir inspiration, not as another trailer for a film or TV show, but in the hope that it is a trailer 'for one part of the next chapter of the human story' (Bishop, 2018). These are the words of Jonathan Noland, one 
of HBO's Westworld creators, who together with Elon Musk conspired to reignite the conversation about space exploration with the help of a red sports car and a David Bowie song. The technological show and its incredible feat of engineering conjured a powerful set of cultural symbols and metaphors (Ibid.).

In this analysis, I focus on the aesthetics of the Tesla Roadster's Starman not as an artwork but as a cultural 'celestial object' as recently termed by NASA (Miley, 2018). The Starman is a dummy driver dressed in a spacesuit. It occupies the driver seat of Elon Musk's Tesla Roadster electric sports car with one hand on the wheel and the other casually resting on the open window, while embarking on a billion years of cosmic trajectory.

Basing her analysis on the anthropologist Victor Turner's argument that a symbol can encompass contradictory meaning, Alice Gorman (2018) writes that the image of the red sports car is on one hand a symbol of 'elite wealth and masculinity' and on the other hand a talisman against death and mortality. Yet, in the void of space, the red sports car changes its colors actually and metaphorically. It becomes an object in eternity.

\subsection{Kabbalistic Technoetic Chariot}

I thus relate to the celestial object as a present-day metaphor of an apocalyptic horse and rider as well as a Kabbalistic technoetic chariot. The notion of a Kabbalistic chariot is brought to mind and enhanced by the roadster's payload entitled the Solar Library by the Arch Mission Library. It consists of the first of its kind storage data discs of the latest technology that are designed to archive human knowledge for billions of years. The roadster carries Arch 1.2 that stores Asimov's Foundation Series, of which the central theme corresponds with the dissemination and preservation of humanity's collective knowledge beyond earth in the Milky Way (Spivack, 2018). This significant addition transforms the car into a carrier of human consciousness or mind similar to the Kabbalistic chariot that functions as the carrier of the nous. The driver as rider is the navigator of the human imagination which, once launched into orbit, is in affinity with, and carried by, the celestial laws of the sublime intellect. Hence, whether the rider is dead or alive is of no relevance at this stage of orbit in which the rider as a symbol of the intellect or the human mind becomes metaphorically, poetically and spiritually transcendent.

The cameras on the car broadcasted to earth directly from space a live webcast, showing an awe-inspiring technological performance. The red car and the white spacesuit lost their uniformity and were immersed in, and 
mixed with, the bluish shades of planet earth, the radiance of the sun, and the deep blackness of the void of space.

\section{The Transcendent Cosmic Rider as Field of Consciousness}

Visually, the colors of the Four Horses of the Apocalypse: white, red, black and pale, are randomly reflected in moving shades on the driver-rider and the car. The artifact seems to subliminally mirror our apocalyptic anxieties along with fears of exploitations of technology. Colors in space look hyper-real and almost unbelievably sharp (Geggel, 2018), thus, for example, the red of the car and the white of the rider could be intensifying the sensibilities of masculine violence and treachery by means of war. Or as the car is gradually enveloped by the depth of blackness, the fear of emptiness may be associated with the mythic famine, seen today in the depletion of earth's resources and in the consequences of climate warming. In striking contrast to the deadly environment of outer space, earth in the webcast appears to embrace her chariot and rider for the last time with her glowing living body and shining blue oceanic eyes.

As part of my ongoing creative practice and research in art as a field of consciousness, and networked mind in networked rites, performance or environment (Moore, 2015, 2018b), I have chosen to reflect on the interrelation between humanity and its symbolic rider that carries a cultural sample of humankind's consciousness to the cosmos. Due to the mass viewing, it was feasible to examine whether the event was registered on the Global Consciousness Project network (GCP) of REGs (Random Event Generators) (Exopolitik, 2015), which explores the interrelations of mind and technology, or mind over matter. Interestingly, the graphs of the data from the entire GCP network during the two-hour period of the SpaceX launch, which were produced by Bryan J Williams, show a modest shift away from expected randomness (in the downward direction), which begins just after the moment of liftoff. The downward trend then continues its steady descent, skirting the threshold of statistical significance (indicated by the curved red arcs). The demonstrated graph shows an unexplained form of seemingly quantum entanglement between the timing of the liftoff and the downward shift (See, Moore, 2018a).

The aesthetics of the graph has triggered further reflections on the poetics of technology and mind. The rider's motion of ascent into outer space contrasts the motion of descent on the graph, thus, producing a two-way trajectory, as well as outward and inward movements. The motion on the graph mirrors the physical gap that was growing between the viewers on earth, which followed the celestial object online, and the latter that was leaving them increasingly behind and downward. Yet, the physical gap 
generated a contradictory sense of noetic closeness and inward movement towards communitas, which is a state of unity best explained by Victor Turner (1969). Downward trends in graphs produced by the Global Consciousness Project usually occur during large group meditation and mass prayer events. According to Bryan J Williams (personal conversation 24 .4. 2018), Roger Nelson explains downward trends as traces of focused intention 'where people are coming together with purpose and with a very heartfelt dedication to a shared positive goal'. Clearly, this graph is not intended here as proof of collective consciousness acting on technology but it serves to aesthetically highlight a valid exploration.

As we have seen in mystical Kabbalistic traditions, the horse and the rider are associated with the human imagination and intellectual capacity to interact with the active intellect. The chariot is a mystical symbol of technology that interacts with the mind. These archaic ideas are reflected in the aesthetics that currently associates the horse and the rider with electric cars and space age technology, and encapsulates humanity in indestructible discs, arches of consciousness, nous as data sent to the cosmos.

\section{Conclusions: Neoteric Senses and Technoetic Modes of Revelation and}

\section{Transcendence}

To summarize, films like Blade Runner 2049 reflect current apocalyptic warnings. The Four Horsemen of the Apocalypse appear as qualities and themes together with the horse in the mind as the transcendent intellect that compels humanity to boldly address its set of ethics: the good, the true and the beautiful (Metz, 2011). These could be provoked unexpectedly and unintentionally by cybernetic systems that enable people to participate and interact with them. The cybernetic system of the Tesla Roadster's launch comprised of three symbolic objects, namely: electric car, figure in a spacesuit and a memory disc, set on an orbit for eternity. It was broadcasted live from space on YouTube, and generated the sense of cyberception.

Cyberception is a technoetic term coined by Roy Ascott (2003b:376). It is a comprehension that arises when dry digital and moist biological systems interlock and give access to two distinctly different fields of experience simultaneously: psychic space and cyberspace, the material world and the virtual outside it. These layers of experience occurred during the Tesla Roadster launch and were amplified by the virtual presence of the participants online as a network of minds becoming a total of a networked mind field united in its purpose. The awe-inspiring view of the slowly gliding car and the objects' unearthly hues produced a space-time of transcendence for the networked mind that contemplated it. 
The experience of the participants involved a sense of being both in the body, and outside the body as participatory mind, which is akin to Abulafia's mystical technique, and other shamanic practices, involving being in and out of the body at the same time. Although many online events currently induce similar states of cyberception in random ways, the context, scale and mass viewing of the Tesla Roadster launch presents an opportunity to examine the aesthetics involved in technoetic terms, speculating on technoetic modes of revelation.

This cultural event showcased today's performance consisting of technology and mind, which reframe and would probably continue to evolve the religious imagination and the art of revelation and transcendence.

\section{Acknowledgments:}

Bryan J Williams has conducted analyses of the data from a worldwide network of random event generators (REGs) maintained by the Global Consciousness Project (http://www.global-mind.org). The Cybernetic Futures Institute, UK sponsored Dr Lila Moore's conference presentation.

\section{References}

Ascott, Roy. (2003a). 'The Museum of the Mind.' (c. 1996). in Ascott, Roy and Shanken, Edward A. (ed.) Telematic Embrace Visionary Theories of Art, Technology and Consciousness, Berkley, Los Angeles and London: University of California Press, p.341.

Ascott, Roy. (2003b). 'Technoetic Aesthetics, 100 Terms and Definitions for the Post-Biological Era' (c.1998) in Ascott, Roy and Shanken, Edward A. (ed.)

Telematic Embrace Visionary Theories of Art, Technology and Consciousness, Berkley, Los Angeles and London: University of California Press, p.376.

Bishop, Bryan. (March 10, 2018). 'Elon Musk and the creator of Westworld made an inspirational trailer for the Falcon Heavy launch'. The Verge. Retrieved April 15 from https://www.theverge.com/2018/3/10/17105322/elonmusk-spacex-falcon-heavy-westworld-jonathan-nolan-trailer-sxsw

Dick, Philip K. (1993). The Selected Letters of Philip K. Dick: 1977-1979. Vol .5. Los Angeles: Underwood Books. 
Exopolitik. (2015 February 3). 'The Global Consciousness Project - Ph.D. Roger Nelson.' [video file]. Retrieved April 15 from https://www.youtube.com/watch?v=HQXoMI130KY

Geggel, Laura. (2018 February 7). 'Why Does the Tesla Look So Fake in Space? We Asked a Chemist.' Live Science. Retrieved April 15 from https://www.livescience.com/61690-why-spacex-roadster-looks-fake.html Gorman, Alice (2018 February 7). 'A Sports Car and a Glitter Ball are Now in Space -What does that Say About Us as Humans?' The Conversation. Retrieved April 15 from https://theconversation.com/a-sports-car-and-a-glitter-ball-arenow-in-space-what-does-that-say-about-us-as-humans-91156

Idel, Moshe. (1987). The Mstical Experience in Abraham Abulafia. Albany, New York: State University of New York Press.

Idel, Moshe. (1990). Golem: Jewish Magical and Mystical Traditions on the Artificial Anthropoid. Albany, New York: State University of New York Press.

Kurzweil, Ray. (2005). The Singularity Is Near: When Humans Transcend Biology . New York: Viking Books

Menn, Stephen. (1992). 'Aristotle and Plato on God as Nous and as the Good'. The Review of Metaphysics. 45: 3, 543-573.

Metz, Thaddeus. (2011).' The Good, the True, and the Beautiful: Toward a Unified Account of Great Meaning in Life.' Religious Studies 47.4: 389-409.

Miley, Jessica. (2018 February 9). 'NASA Officially Lists Elon Musk's Floating Tesla Roadster As a Celestial Object.' Interesting Engineering. Retrieved April 15 from https://interestingengineering.com/nasa-officially-lists-elon-musksfloating-tesla-roadster-as-a-celestial-object

Moore, Lila. (2015). Fields of Networked Mind: Ritual Consciousness and the Factor of Communitas in Networked Rites of Compassion. Technoetic Arts: A Journal of Speculative Research, 13: 3, 331-339.

Moore, Lila. (in press, 2018b). 'The Shaman of Cybernetic Futures: Art, Ritual and Transcendence in Fields of the Networked Mind', Cybernetics \& Human Knowing. 25: 2-3.

Moore, Lila (2018a July 10). 'Technoetic Aesthetics of Revelation and Transcendence: The Horse in the Mind.' [video file]. Retrieved September 29, 2018 from https://www.cyberneticinstitute.com/singlepost/2018/07/10/Technoetic-Aesthetics-of-Revelation-and-Transcendence-TheHorse-in-the-Mind 
SpaceX. (2018 March 10). 'Falcon Heavy \& Starman,' Retrieved April 15, 2018 from https://www.youtube.com/watch?v=A0FZIwabctw

Spivack, Nova. (2018 February 7). 'Arch Mission Foundation Announces Our Payload On SpaceX Falcon Heavy.' Medium. Retrieved April 15 from https://medium.com/arch-mission-foundation/arch-mission-foundationannounces-our-payload-on-spacex-falcon-heavy-c4c9908d5dd1

Tikunei haZohar. English Tikkunei Partial 1-17 out of 70. Retrieved September 29, 2018 from https://drive.google.com/file/d/0BwRFZRSGYc3Q2R6WDZZbEtRUEU/view

Turner, Victor (1969), The Ritual Process Structure and Anti-Structure, Ithaca, NY: Cornell University Press. 